\title{
n3 and n6 polyunsaturated fatty acids differentially modulate prostaglandin E secretion but not markers of lipogenesis in adipocytes
}

\author{
Patrick Wortman ${ }^{1}$, Yuko Miyazaki ${ }^{1}$, Nishan S Kalupahana1,2,3, Suyeon Kim¹, \\ Melissa Hansen-Petrik ${ }^{3}$, Arnold M Saxton ${ }^{1,2}$, Kate J Claycombe ${ }^{5}$, \\ Brynn H Voy ${ }^{1,2,4}$, Jay Whelan ${ }^{3}$ and Naima Moustaid-Moussa*1,2
}

\begin{abstract}
Address: ${ }^{1}$ University of Tennessee (UT), Department of Animal Science, Knoxville, TN, USA, ${ }^{2}$ University of Tennessee (UT), UT Obesity Research Center, Knoxville, TN, USA, ${ }^{3}$ University of Tennessee (UT), Department of Nutrition, Knoxville, TN, USA, ${ }^{4}$ Oak Ridge National laboratory, Oak Ridge TN, USA and ${ }^{5}$ Michigan State University, Department of Food Science and Human Nutrition, Lansing, MI, USA

Email: Patrick Wortman - PWortman@cim.md; Yuko Miyazaki - yukom77@hotmail.com; Nishan S Kalupahana - nkalupah@utk.edu; Suyeon Kim - skim@jax.org; Melissa Hansen-Petrik - phansen@utk.edu; Arnold M Saxton - asaxton@utk.edu;

Kate J Claycombe - claycom3@msu.edu; Brynn H Voy - voybh@ornl.gov; Jay Whelan - jwhelan@utk.edu; Naima Moustaid-

Moussa* - moustaid@utk.edu

* Corresponding author
\end{abstract}

Published: 21 January 2009

Nutrition \& Metabolism 2009, 6:5 doi:10.1 186/1743-7075-6-5
Received: 27 August 2008

Accepted: 21 January 2009

This article is available from: http://www.nutritionandmetabolism.com/content/6/1/5

(C) 2009 Wortman et al; licensee BioMed Central Ltd.

This is an Open Access article distributed under the terms of the Creative Commons Attribution License (http://creativecommons.org/licenses/by/2.0), which permits unrestricted use, distribution, and reproduction in any medium, provided the original work is properly cited.

\begin{abstract}
A dramatic rise in the incidence of obesity in the U.S. has accelerated the search for interventions that may impact this epidemic. One recently recognized target for such intervention is adipose tissue, which secretes a variety of bioactive substances including prostaglandins. Prostaglandin $E_{2}$ $\left(\mathrm{PGE}_{2}\right)$ has been shown to decrease lipolysis in adipocytes, but limited studies have explored alternative mechanisms by which $\mathrm{PGE}_{2}$ might impact obesity, such as adipogenesis or lipogenesis. Studies conducted on $\mathrm{ApcMin/+}$ mice indicated that selective inhibition of the cyclooxygenase (COX)-2 enzyme led to significant reductions in fatty acid synthase (FAS) activity in adipose tissue suggesting lipogenic effects of $\mathrm{PGE}_{2}$. To further investigate whether these lipid mediators directly regulate lipogenesis, we used 3T3-LI adipocytes to determine the impact of eicosapentaenoic acid (EPA) and celecoxib on PGE $_{2}$ formation and $F A S$ used as a lipogenic marker. Both arachidonic acid (AA) and EPA dose-dependently increased PGE secretion from adipocytes. AA was expectedly more potent and exhibiting at I50 uM dose a 5 -fold increase in PGE $_{2}$ secretion over EPA. Despite higher secretion of PGE by EPA and AA compared to control, neither PUFA significantly altered FAS activity. By contrast both AA and EPA significantly decreased FAS mRNA levels. Addition of celecoxib, a selective COX-2 inhibitor, significantly decreased $P G E_{2}$ secretion $(P<0.05)$ versus control, and also significantly decreased FAS activity $(p<0.05)$. Unexpectedly, the combination of exogenous $\mathrm{PGE}_{2}$ and celecoxib further decreased the FAS activity compared to $\mathrm{PGE}_{2}$ alone or untreated controls. In conclusion, EPA-mediated inhibition of AA metabolism did not significantly alter FAS activity while both AA and EPA significantly decreased FAS mRNA expression. COX-2 inhibition significantly decreased $\mathrm{PGE}_{2}$ production resulting in a decrease in $\mathrm{FAS}$ activity and expression that was not reversed with the addition of exogenous $\mathrm{PGE}_{2}$, suggesting an additional mechanism that is independent of COX-2.
\end{abstract}




\section{Background}

Several bioactive molecules and hormones have been reported to be secreted by adipose tissue $[1,2]$. Related to our current work, the secretion of prostaglandins such as prostaglandin $\mathrm{E}_{2}\left(\mathrm{PGE}_{2}\right)$ has been shown in human and rodent adipocytes [3-7]. Further, the presence of prostaglandin $\mathrm{E}$ receptors $\left(\mathrm{EP}_{1-4}\right)$ in these tissues as well [8-10] has led to research into a possible autocrine or paracrine role for this Arachidonic Acid (AA) metabolite. Several studies reported antilipolytic roles for $\mathrm{PGE}_{2}$ in cultured adipocytes and adipose tissue explants [11-13], most likely acting through a G-inhibitory protein-coupled $\mathrm{EP}_{3}$ receptor [14], confirming a paracrine/autocrine role of $\mathrm{PGE}_{2}$ in adipocytes. Additional roles for $\mathrm{PGE}_{2}$ in adipocytes include increased secretion of leptin release from mouse adipose tissue [15] and decreased hepatic lipogenic gene expression [16]. These studies did not, however, address whether $\mathrm{PGE}_{2}$ also exerts lipogenic or adipogenic effects in adipocytes.

Several studies have explored regulation of hepatic lipogenesis by polyunsaturated fatty acids (PUFA) $[17,18]$. However, these effects may be tissue specific as hepatic and adipose lipogenesis may be differentially regulated [19]. Arachidonic acid (AA, 20:4 n-6) has been shown to stimulate glucose intake in adipocytes by increasing glucose receptor levels in the cell membranes [20] potentially increasing substrate availability for de novo lipogenesis. $\mathrm{AA}$ is also the preferential substrate for the cyclooxygenase $(\mathrm{COX})$ enzymes, resulting in production of PG and other metabolites $[21,22]$. In mature adipocytes, $\mathrm{PGE}_{2}$ is the primary PG produced from the COX pathway [23-26].

In most cases, AA and dietary eicosapentaenoic acid (EPA, 20:5 n-3) exert opposing effects; however, hepatic lipogenesis is downregulated by both fatty acids $[16,27,28]$. EPA impacts adipocyte biological functions via two distinct mechanisms. The first is via transcriptional activation of lipogenic and adipogenic genes by binding to nuclear receptors such as PPARgamma. The second mechanism is via direct competition with AA for incorporation into membrane phospholipids and subsequent conversion to eicosanoids including PGs. While the first mechanism has been extensively studied, few studies have addressed the second mechanism in adipocytes. Synthesized or preformed AA is incorporated into the sn-2 position of cell membrane phospholipids and subsequently liberated by phospholipases $\left(\mathrm{CPLA}_{2}\right)$. COX metabolizes AA into $\mathrm{PGE}_{2}$, which is then secreted by the cell to act in an autocrine/paracrine fashion via specific EP receptors. EPA competes with AA for incorporation into cell membrane phospholipids and for the active site on the COX enzymes when $\mathrm{CPLA}_{2}$ is activated. This competition and the resulting production of $\mathrm{PGE}_{3}$ when $\mathrm{COX}$ metabolizes EPA, could result in decreased levels of $\mathrm{PGE}_{2}$.
Decreased PGs production, and particularly $\mathrm{PGE}_{2}$, by COX-2 inhibitors has been demonstrated in adipocytes [4,29-31]. Further, initial in vivo studies demonstrated that inhibition of $\mathrm{PGE}_{2}$ synthesis decreased FAS activity in mouse adipose tissue and this was largely reversed by cotreatment with $\mathrm{PGE}_{2}$ receptor agonist. We hypothesized that these effects reflected direct actions of $\mathrm{PGE}_{2}$ (or its modulators, PUFA or COX ligands) on adipose tissue. Specifically we tested whether manipulation of $\mathrm{PGE}_{2}$ levels by addition of EPA (dietary intervention) or selective COX-2 inhibition (pharmaceutical intervention) decreases $\mathrm{PGE}_{2}$ production from adipocytes and subsequently downregulates FAS enzyme activity. If $\mathrm{AA}$ and EPA modulate FAS activity or expression via changes in $\mathrm{PGE}_{2}$ levels, it is then expected that these fatty acids exert opposite effects on FAS expression. We performed a series of experiments in cultured adipocytes which provide compelling evidence that PUFA effects on adipose tissue FAS were independent of changes in PGE levels.

\section{Materials and methods Experiment Design}

Animal Experiments

Male C57BL/6J Apc Min/+ mice (Jackson Labs, Bar Harbor, $\mathrm{ME}$ ) were obtained at 4-6 weeks of age. Mice were housed in a temperature-controlled room with $14 \mathrm{~h}$ periods of light and $10 \mathrm{~h}$ periods of darkness and given free access to food and water. The health of the animals was checked daily. Food was withheld overnight prior to sacrifice. All animal procedures were approved by the University of Tennessee Animal Care and Use Committee. Mice were fed a purified AIN-93G powder diet (Dyets, Inc., Bethlehem, PA). Diets containing drug treatments were prepared daily by thoroughly mixing the drugs with the AIN-93G diet to achieve desired drug dosage. Diets were stored at $20^{\circ} \mathrm{C}$ and all animals were provided fresh food daily. Food consumption was monitored daily and body weights were recorded weekly.

We used the C57BL/6J $A p c^{\mathrm{Min} /+}$ mice which we have previously shown to be highly responsive to pharmacological and dietary manipulations of $\mathrm{PGE}_{2}[32,33]$. The experimental design we used has been previously described [32]. Briefly, male $\mathrm{C} 57 \mathrm{BL} / 6 \mathrm{~J} A p c^{\mathrm{Min} /+}$ mice were maintained on the AIN-93G diet until approximately 80 days of age at which time they were randomly assigned to treatment groups consisting of control, E-prostaglandin receptor agonists (EPR-A) [16,16-dimethyl-PGE 2 and 17phenyl-trinor $\mathrm{PGE}_{2}$ (Cayman Chemical, Ann Arbor, MI), $10 \mu \mathrm{g}$ each], COX inhibitor (piroxicam [Sigma, St. Louis, MO], $0.5 \mathrm{mg} / \mathrm{mouse} /$ day), or piroxicam + EPR-A. The mice were sacrificed at 11-12 weeks of age and epididymal adipose tissue was harvested, weighed, snap frozen in liquid nitrogen and stored at $-80^{\circ} \mathrm{C}$ until further analysis. 


\section{Cell Culture Experiments}

3T3-L1 preadipose cells were purchased from American Type Culture Collection (ATCC, Rockville, MD) and were grown in $100 \mathrm{~mm}$ dishes. Culture medium was composed of Dulbecco's modified Eagle's medium (DMEM) supplemented with 10\% fetal bovine serum (FBS) and 1\% penicillin/streptomycin $(\mathrm{P} / \mathrm{S})$. Cells were plated on day 1 ( 200,000 cells/100 mm dish) and grown for 3-4 days to confluence. At confluence, media was changed and supplemented with $250 \mathrm{nM}$ Dex, $0.5 \mathrm{mM}$ Mix, and $10 \mathrm{nM}$ insulin for $48 \mathrm{~h}$ to induce adipocyte differentiation, after which cells were cultured with regular media supplemented with insulin. Differentiation was considered complete at 5-7 days post-confluence. Twenty-four hours prior to treatment, regular media was replaced with starvation media consisting of DMEM, P/S, and $1 \%$ fatty acidfree bovine serum albumin (BSA). Treatment media consisted of starvation media $+10 \mathrm{nM}$ insulin and individual (FA or inhibitor) treatments. Because fatty acids are primarily found in the circulation as bound to albumin and numerous studies have used this form of the fatty acid for cell culture studies [34,35], all fatty acids in our experiments were conjugated with BSA prior to the treatment. Fatty acids were diluted in DMSO, added to the treatment media and incubated in a shaking water bath for 2 hours at $37^{\circ} \mathrm{C}$ to facilitate this binding. All treatments lasted 48 hours. Fatty acids were purchased from Nu-Check Prep, Inc., Elysian, MN. All studies were conducted in cells that were at least $80-95 \%$ differentiated as assessed by lipid accumulation to insure findings are attributed to differentiated rather than undifferentiated fat cells. Detailed experimentation is described below:

\section{Dose response studies for $A A$ and $E P A$ on $P G E_{2}$}

Dose response studies were conducted to determine physiological EPA dose that would significantly reduce $\mathrm{PGE}_{2}$ levels when compared to an equivalent concentration of AA. 3T3-L1 adipocytes were treated with AA or EPA (NuCheck Prep, Inc., Elysian, MN) in 25, 50, 100, 200, and $500 \mu \mathrm{M}$ doses. Stock solutions of fatty acids were prepared in dimethyl sulfoxide (DMSO). Treatment time was $48 \mathrm{~h}$ for all doses. Cell culture media was collected to measure secreted $\mathrm{PGE}_{2}$ levels and cells were harvested to prepare cytosolic extracts used to measure FAS activity.

\section{Effects of COX inhibition and various fatty acids and PGE $E_{2}$ on FAS}

To determine whether treatment of adipocytes with EPA reduces $\mathrm{PGE}_{2}$ production by reducing COX enzyme activity, cells were treated with EPA $(50 \mu \mathrm{M}$ and $150 \mu \mathrm{M})$, COX-2 inhibitor (celecoxib or CI, $5 \mu \mathrm{M}$ ) (Pharmacia, St. Louis, MO), and a combination of EPA $(150 \mu \mathrm{M})+\mathrm{CI}(5$ $\mu \mathrm{M})$. In addition, as a positive control for fat peroxidation, EPA at $150 \mathrm{uM}$ was also added alone to culture media without cells. Treatments lasted 48 hrs, and cell culture media were then collected to measure PGE 2 levels and cells were harvested for cytosolic extracts. In a second set of experiments, cell cultures were treated with vehicle (DMSO), CI (1 $\mu \mathrm{M})$, oleic acid (OA, 18:1 n-9), EPA, AA (150 $\mu \mathrm{M}$ each treatment) or AA + EPA (75 $\mu \mathrm{M}$ each fatty acid); media was removed from each dish, and cell cultures were harvested for cytosolic extracts or total RNA.

\section{Effect of $P G E_{2}$ supplementation on FAS}

To confirm that $\mathrm{PGE}_{2}$ was responsible for the decrease in FAS activity seen with selective COX-2 suppression, $\mathrm{PGE}_{2}$ was added back to mean levels measured in the control groups of previous experiments. 3T3-L1 cell cultures were treated with vehicle (DMSO), CI $(1 \mu \mathrm{M}), \mathrm{PGE}_{2}(300 \mathrm{pM})$ (Cayman Chemical, Ann Arbor, MI), and CI + PGE 2.48 hours following treatment, two mL of media was removed from each dish, and cells were harvested for cytosolic extracts or total RNA.

\section{FAS assay}

The activity of FAS was determined in cytosolic extracts from mouse adipose tissue and cell culture by measuring the rate of oxidation of NADPH as previously described [36]. Briefly, mouse adipose tissue collected from experiment 1 was homogenized on ice in $500 \mu \mathrm{L}$ of sucrose buffer ( $\mathrm{pH}$ 7.4). Cell culture plates harvested for cytosolic extracts were washed twice in Hank's balanced salt solution, and then scraped using $350 \mu \mathrm{L}$ of sucrose buffer. Cell homogenates were sonicated on ice for 5 seconds. Tissue and cell culture homogenates were centrifuged for $1 \mathrm{~h}$ $(12,000 \times \mathrm{g})$ at $4^{\circ} \mathrm{C}$. The supernatant was then removed for analysis of FAS activity and protein concentration.

\section{Protein assay}

Protein concentration was determined in cytosolic extracts by the method of Bradford [37], using Coomassie blue reagent (Bio-Rad, Melville, NY). Each sample was measured in duplicate using $10 \mu \mathrm{L}$ of sample and $200 \mu \mathrm{L}$ of dye in a 96-well plate. After addition of the dye, the samples were incubated for 5 minutes and read in a spectrophotometer at $590 \mathrm{~nm}$. A standard curve was plotted using serial dilutions of a BSA standard of known concentration and sample concentrations were extrapolated based on this standard curve.

\section{$\mathrm{PGE}_{2}$ assay}

Cell culture $\mathrm{PGE}_{2}$ concentrations were determined using culture media samples obtained immediately prior to cell harvest. $\mathrm{PGE}_{2}$ levels were measured by enzyme immunoassay (EIA) using the Correlate-EIA PGE 2 Kit (Assay Designs, Ann Arbor, MI) according to the manufacturer's instructions. A standard curve was plotted using serial dilutions of a known concentration of $\mathrm{PGE}_{2}$ and sample concentrations were extrapolated based on this standard curve. PGE 2 EIA assay cross- reactivity for $\mathrm{PGE}_{3}$ is reported by the manufacturer to be $16.3 \%$. 


\section{Real time RT-PCR}

Real time RT-PCR was used to determine FAS mRNA expression. Cells harvested for total RNA were scraped in $350 \mu \mathrm{L}$ of Qiazol lysis reagent (Qiagen, Valencia, CA) and sonicated on ice for 5 seconds. RNA was extracted using the $\mathrm{RNeasy}^{\mathrm{TM}}$ lipid tissue midi kit (Qiagen) following the manufacturer's protocol. RNA was stored at $-80^{\circ} \mathrm{C}$ for use in real time RT-PCR. Two micrograms of RNA was used to synthesize cDNA. The FAS primers were ordered from Invitrogen (Carlsbad, CA). The sequence of the forward primer was 5'CCCAGAGGCTTGTGCTGACT 3' and the sequence of the reverse primer was 5'CGAATGTGCTTGGCTTGGT 3'. The probe was ordered from Biosearch Technologies, Inc. (Novato, CA). The sequence of the probe was 5'(TET)CCGATCTGGAATCCGCACCGG(TAMRA) 3'. TET is the quencher dye that inhibits the fluorescence of the reporter dye when in close proximity. TAMRA is the reporter dye and is measured at a wavelength of $580 \mathrm{~nm}$. The reactions were performed using the SmartCycler SC1000-1 (one cycle each at $48^{\circ} \mathrm{C} * 1,800$ sec and $95^{\circ} \mathrm{C} * 600 \mathrm{sec}$ followed by 40 cycles at $95^{\circ} \mathrm{C} *$ $15 \mathrm{sec}$ and $\left.60^{\circ} \mathrm{C} * 60 \mathrm{sec}\right)$ and analysed using SmartCycler software (Cepheid, Sunnyvale, CA).

\section{Statistical analysis}

Statistical analysis for all assays was conducted using SPSS (SPSS for windows, version 12.0, SPSS Inc., Chicago, IL). Data were analyzed for homogeneity of variance and for significant F-ratios between treatment groups using oneway analysis of variance (ANOVA). Post-hoc analysis was conducted using the Bonferroni (equal variance) or Dunnett's T3 (unequal variance) test when significant differences were detected. All values are expressed as mean + SEM. Values of $\mathrm{p}<0.05$ were considered statistically significant except where otherwise noted.

\section{Results}

Effect of COX inhibition and EP receptor agonists on FAS activity in mouse adipose tissue

Several studies including ours have previously shown that inhibition of the cyclooxygenase enzymes decrease prostaglandin levels and tumor load in the $A p c^{\mathrm{Min} /+}$ mouse model and that these effects can be reversed by addition of prostaglandin E2 [32]. To determine whether this inhibition also affects fat synthesis, and specifically whether a lipogenic enzyme, FAS, is regulated by prostaglandin levels, adipose tissue from mice treated with vehicle, COX enzymes inhibitor piroxicam and/or EP receptor agonists were studied. As shown in Fig 1, piroxicam significantly decreased FAS activity (4-fold reduction, $\mathrm{p}<0.01$ ); similar effects were obtained with another COX inhibitor, sulindac (Data not shown). Combined piroxicam + EP receptor agonists treatments resulted in significant partial restoration of FAS activity $(\mathrm{p}<0.02)$. Treatment with EP receptor agonists alone also resulted in a significant reduction in FAS activity when compared to control $(\mathrm{p}<0.02)$.

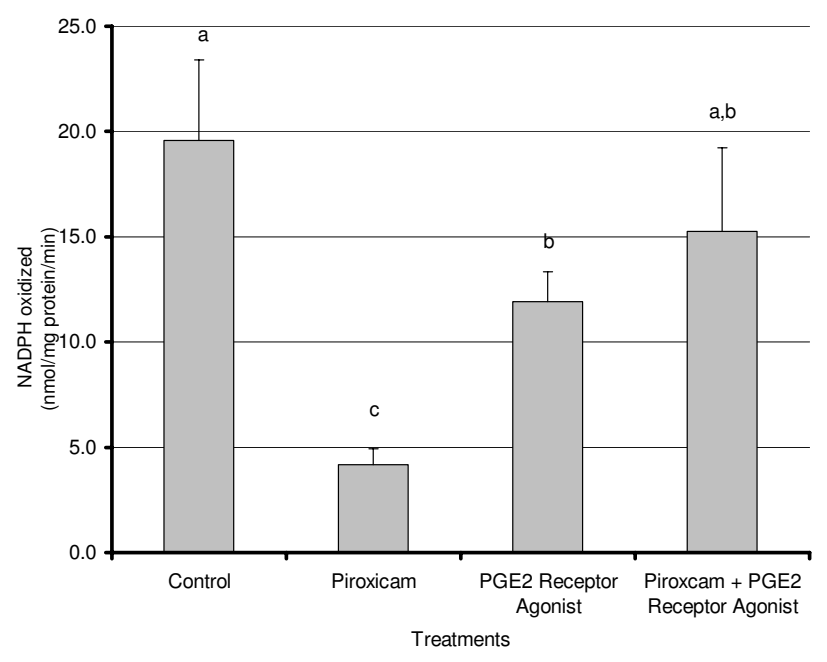

Figure I

Effects of piroxicam and $\mathrm{PGE}_{2}$ receptor agonists onadipose FAS activity in ApcMin/+ mice. Male C57BL/6] Apc $\mathrm{Min} /+$ mice were maintained on the AIN-93G diet until approximately 80 days of age at which time they were randomly assigned to treatment groups. Treatments consisted of control, piroxicam $(0.5 \mathrm{mg} / \mathrm{mouse} /$ day $)$, EPR-A (I6, I6dimethyl-PGE ${ }_{2}$ and I7-phenyl-trinor $\mathrm{PGE}_{2}-10 \mu \mathrm{g}$ each), or piroxicam + EPR-A. Mice were sacrificed after 6 days of treatment and epididymal adipose tissue was harvested and snap frozen in liquid nitrogen. Tissue was homogenized in sucrose buffer and cytosolic extracts were analyzed for FAS activity using an activity assay as described in Materials and Methods. For treatments $C$ and $P+E P R-A n=6$; for $P$ and EPR-A $n=5$. Results represent the mean \pm SEM. Values labeled with different letters are significantly different $(p<$ 0.05 ). Values with the same letters do not differ significantly.

\section{Dose-Response effect of EPA and AA on $P_{G} E_{2}$ secretion and FAS activity in 3T3-LI adipocytes}

Consistent with studies that have shown the displacement of AA by EPA in tissue phospholipids [33,38-40], the levels of $\mathrm{PGE}_{2}$ were significantly lower when EPA was added to the cell culture media compared to equivalent concentrations of AA (Fig. 2). As expected, addition of AA led to a powerful dose-dependent increase in $\mathrm{PGE}_{2}$ production. The two highest doses of EPA $(200 \mu \mathrm{M}$ and $500 \mu \mathrm{M})$ resulted in $\mathrm{PGE}_{2}$ levels that were significantly higher than control ( $\mathrm{p}<0.03)$, although this is most likely attributed to the formation of $\operatorname{PGE}_{3}[39,41]$. However, at the doses tested above, FAS enzyme activity did not exhibit any significant changes from control, following AA or EPA treatments except for AA at $500 \mu \mathrm{M}(\mathrm{p}<0.03)$ which was significantly higher than control (data not shown).

\section{Effect of EPA versus COX inhibition (CI) on PGE levels in 3T3-LI adipocytes}

Antagonistic effects of EPA and AA have been extensively studied and reported and in most cases, EPA effects mimic effects of COX inhibition. Increasing doses of EPA as 


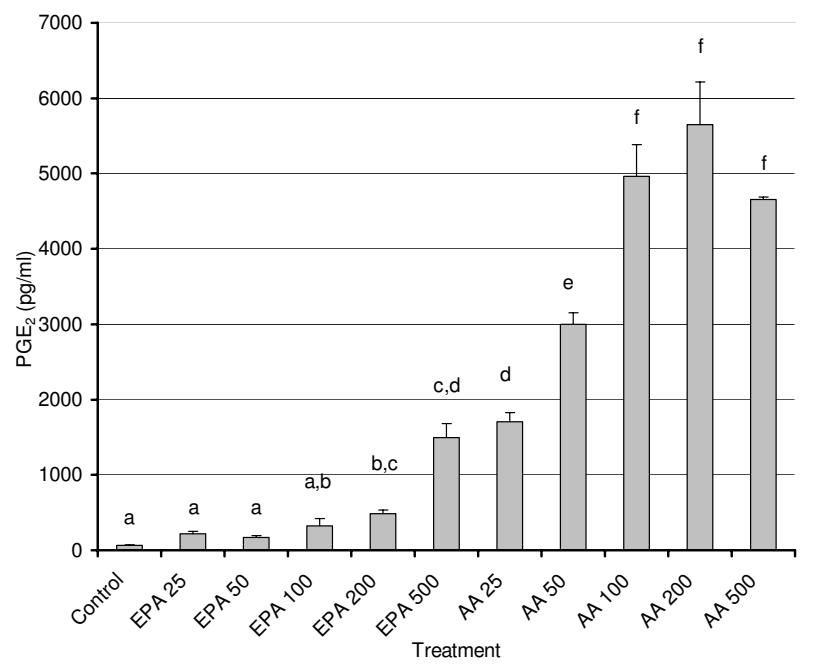

Figure 2

Dose-response effects of AA and EPA on PGE levels $_{2}$ in 3T3-LI adipocytes. 3T3 L-I adipocytes were grown 6-7 days post-confluence, and starved for $24 \mathrm{~h}$ in serum-free media containing FA-free BSA. Fatty acids were incubated in media containing FA-free BSA for two hours at $37^{\circ} \mathrm{C}$ in a shaking water bath prior to treatment. Treatment consisted of AA and EPA at 25, 50, 100, 200, and $500 \mu \mathrm{M}$ concentrations. After 48 hours, media was removed and stored at $80^{\circ} \mathrm{C}$ until $\mathrm{PGE}_{2}$ levels were measured as described in the Materials and Methods. For treatments AA/EPA $500 n=5$; control (C) and AA/EPA $25 n=10$; AA/EPA 50, 100, $200 n=$ 15. Values labeled with different letters are significantly different $(p<0.05)$. Results represent the mean \pm SEM. Values with the same letters do not differ significantly.

reported in Fig. 2 led to increased PGE $_{2}$ levels, presumably due to the formation of $\mathrm{PGE}_{3}$ (41) as the antibody had a weak cross reactivity of $\mathrm{PGE}_{3}$ with the $\mathrm{PGE}_{2}$. Addition of $\mathrm{CI}+\mathrm{EPA}(150 \mu \mathrm{M})$ led to a significant reduction in $\mathrm{PGE}_{2}$ ( $\mathrm{p}<0.01)$ (Fig. 3), indicating that the PGE formation is for the most part an enzymatic process. Addition of EPA in the absence of cultured cells led to extremely low levels of PGE confirming that the observed effects were not a consequence of non-specific lipid peroxidation and that increased $\mathrm{PGE}_{2}$ levels measured in EPA treated cell cultures, supporting the likelihood of $\mathrm{PGE}_{3}$ formation, which is detectable with the $\mathrm{PGE}_{2}$ immunoassay used. Our data consistently show that the $\mathrm{PGE}_{2}$ formation is an enzymatic process, and since no exogenous AA was added to the cells these data collectively support the idea that production of $\mathrm{PGE}_{3}$ is responsible for the increases seen in measured $\mathrm{PGE}_{2}$ production versus control.

Effect of selective COX-2 inhibition and different fatty acids on $\mathrm{PGE}_{2}$ levels, FAS activity and FAS mRNA levels in 3T3-L1 adipocytes

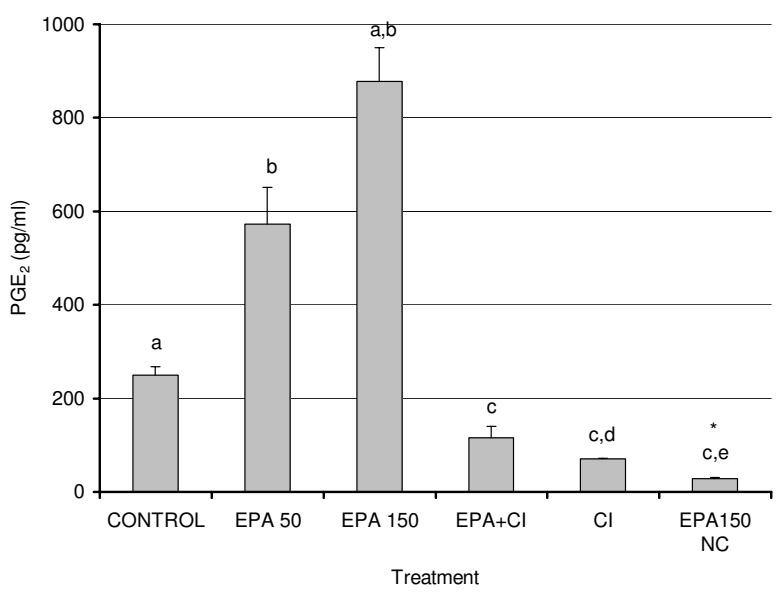

Figure 3

Effects of EPA and COX-2 inhibition on secreted PGE $_{2}$ levels from 3T3-LI adipocytes. 3T3 $\mathrm{L}-\mathrm{I}$ adipocytes were grown 6-7 days post-confluence, and starved for $24 \mathrm{~h}$ in serum-free media containing FA-free BSA. Fatty acids were incubated in media containing FA-free BSA for two hours at $37^{\circ} \mathrm{C}$ in a shaking water bath prior to treatment. Treatment consisted of EPA (50 and I50 $\mu \mathrm{M})$, EPA $(150 \mu \mathrm{M})+\mathrm{Cl}(5$ $\mu \mathrm{M}), \mathrm{Cl}(5 \mu \mathrm{M})$ and EPA (I50 $\mathrm{MM})$ in media without cells. After 48 hours, $2 \mathrm{~mL}$ of media was removed and stored at $80^{\circ} \mathrm{C}$. Media $\mathrm{PGE}_{2}$ levels were analyzed using EIA as described in the Materials and Methods. Results represent the mean \pm SEM with a number of treatments $n=3-4$. Values labeled with different letters are significantly different ( $P$ $<0.05$ ). Values with the same letters do not differ significantly. * Denotes culture media exposed to cell culture conditions without cells.

As shown above, AA significantly increased $\mathrm{PGE}_{2}$ levels in 3T3-adipocytes and to a lesser extent, EPA also increased PGE levels. PGE 2 levels were effectively reduced compared to control by the addition of CI $(\mathrm{p}<0.001)$. All fatty acid treatments resulted in measured increases in concentrations of PGE compared to control, with responsiveness increasing in the order of OA $(\mathrm{p}<0.05),<\mathrm{EPA}<\mathrm{AA}+\mathrm{EPA}$ $<\mathrm{AA}$ (all $\mathrm{p}<0.001$ ) (Fig. 4A). Consistent with the decrease in $\mathrm{PGE}_{2}$ levels by CI, FAS enzyme activity was significantly decreased by COX inhibition ( $\mathrm{p}<0.05$ ); however, EPA and OA exhibited only trends in decreasing FAS activity without reaching statistical significance (Fig. 4B).

Expression of FAS mRNA showed significant changes with COX inhibition and with AA and EPA treatment compared to control ( $\mathrm{p}<0.05$ ) (Fig. 5). The level of reduction of FAS mRNA by the FA treatments correlated well with the degree of unsaturation and chain length and may therefore reflect a non-specific PUFA effect as previously reported for PUFA effects on hepatic lipogenic genes $[42,43]$. 

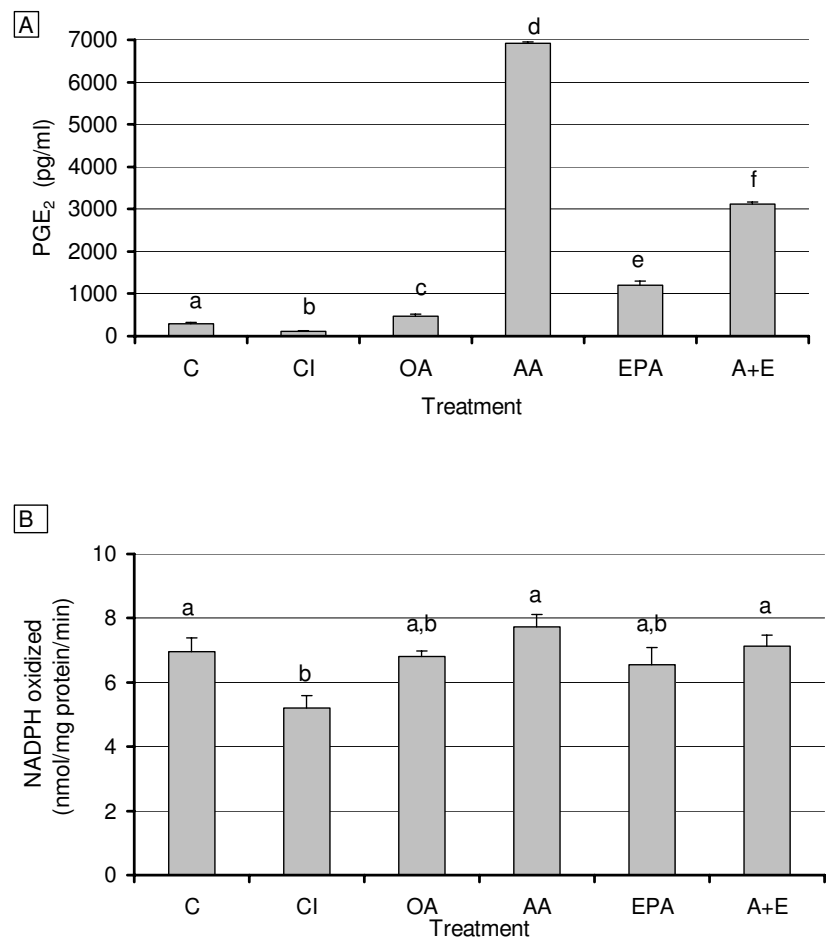

Figure 4

Effects of COX-2 inhibition and EPA addition on PGE $_{2}$ levels (4A) and FAS activity (4B). 3T3 L-I adipocytes were grown 6-7 days post-confluence, and starved for $24 \mathrm{~h}$ in serum-free media containing FA-free BSA. Fatty acids were incubated in media containing FA-free BSA for two hours at $37^{\circ} \mathrm{C}$ in a shaking water bath prior to treatment. Treatment consisted of $\mathrm{Cl}(\mathrm{I} \mu \mathrm{M}), \mathrm{OA}, \mathrm{EPA}, \mathrm{AA}$ (I50 $\mu M$ each treatment), and AA + EPA (75 $\mu$ M each FA). After 48 hours, $2 \mathrm{~mL}$ of media was removed, and cells were scraped using $350 \mu \mathrm{L}$ of sucrose buffer, sonicated, and centrifuged for I hour. Media and cytosolic extracts were stored at $-80^{\circ} \mathrm{C}$. Media $\mathrm{PGE}_{2}$ levels and FAS activity were measured as described in the Materials and Methods. For all treatments $\mathrm{n}$ $=10$. Results represent the mean \pm SEM. Values labeled with different letters are significantly different $(p<0.05)$. Values with the same letters do not differ significantly.

Effect of exogenously added $\mathrm{PGE}_{2}$ on selective COX-2 inhibition of endogenous $P G E_{2}$ secretion, FAS activity, and FAS mRNA levels in 3T3-LI adipocytes

As demonstrated in our previous experiments, addition of $\mathrm{CI}$ resulted in a significant decrease in $\mathrm{PGE}_{2}$ production ( $\mathrm{p}$ $<0.04$ ). Addition of $\mathrm{PGE}_{2}$ to cells treated with $\mathrm{CI}$ restored $\mathrm{PGE}_{2}$ levels and resulted in significantly higher levels versus CI treatment alone or versus control $(\mathrm{p}<0.02)$ (Fig. 6A). Addition of $\mathrm{PGE}_{2}$ to cultures without $\mathrm{CI}$ resulted in the expected significant increases of $\mathrm{PGE}_{2}$ over control levels ( $\mathrm{p}<0.02)$. The level of $\mathrm{PGE}_{2}$ added was based on the mean of previously measured levels of $\mathrm{PGE}_{2}$ secreted by 3T3-L1 control groups (300 pM). Analysis of FAS enzyme

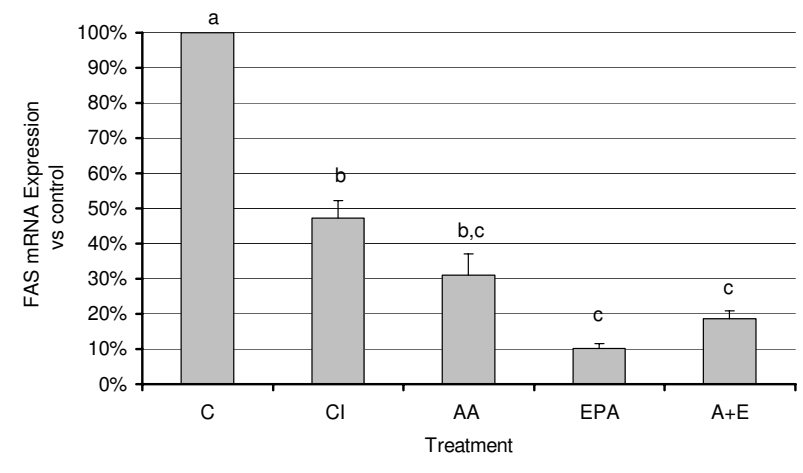

Figure 5

Effects of n3 and n6 PUFA and COX-2 inhibition on FAS mRNA expression. 3T3 $\mathrm{L}-\mathrm{I}$ adipocytes were grown 6-7 days post-confluence, and starved for $24 \mathrm{~h}$ in serum-free media containing FA-free BSA. Fatty acids were incubated in media containing FA-free BSA for two hours at $37^{\circ} \mathrm{C}$ in a shaking water bath prior to treatment. Treatment consisted of $\mathrm{Cl}(\mathrm{I} \mu \mathrm{M})$, EPA and AA (I50 $\mu \mathrm{M}$ each treatment), and AA + EPA (75 $\mu \mathrm{M}$ each FA). After 48 hours, cells were scraped using $350 \mu \mathrm{L}$ of Qiazol lysis reagent, and total RNA was extracted using the RNeasy ${ }^{\mathrm{TM}}$ lipid tissue midi kit (Qiagen) following the manufacturer's protocol. RNA was stored at $80^{\circ}$ for further analysis. Real time RT-PCR analysis was performed as described in the materials and methods. For all treatments $n=6$. Results represent the mean \pm SEM. All values were significantly different than control, and values labeled with different letters are significantly different $(p<$ $0.05)$ from each other. Values with the same letters do not differ significantly.

activity and mRNA expression, however, produced unexpected results regarding $\mathrm{CI}$ and $\mathrm{PGE}_{2}$ interactions. Treatment with CI resulted in a consistent decrease in FAS enzyme activity while combined CI and exogenous PGE $_{2}$ resulted in a significant and further decrease in FAS activity $(\mathrm{p}<0.03)$ rather than the hypothesized reversal of CI inhibition by $\mathrm{PGE}_{2}$ (Fig. 6B). Similar effects were also observed on FAS mRNA (not shown). Addition of $\mathrm{PGE}_{2}$ alone, in the absence of $\mathrm{CI}$, exerted no significant changes on FAS.

\section{Discussion}

We and others have previously shown that adipocytes secrete significant amounts of prostaglandins [3-7,30]. Further, it is well established that $\mathrm{PGE}_{2}$ decreases lipolysis in adipocytes [11-14]. Our current study addressed whether $\mathrm{PGE}_{2}$ also induces lipogenic activities in adipocytes, which could further enhance their hypertrophic effects in these cells. We have previously reported responsiveness of the $A p c^{\mathrm{Min} /+}$ mice to changes in prostaglandin levels [35]. In this study we tested whether changes in prostaglandins modulated fatty acid synthesis in adipose tissue of these mice. We demonstrated that inhibition of 

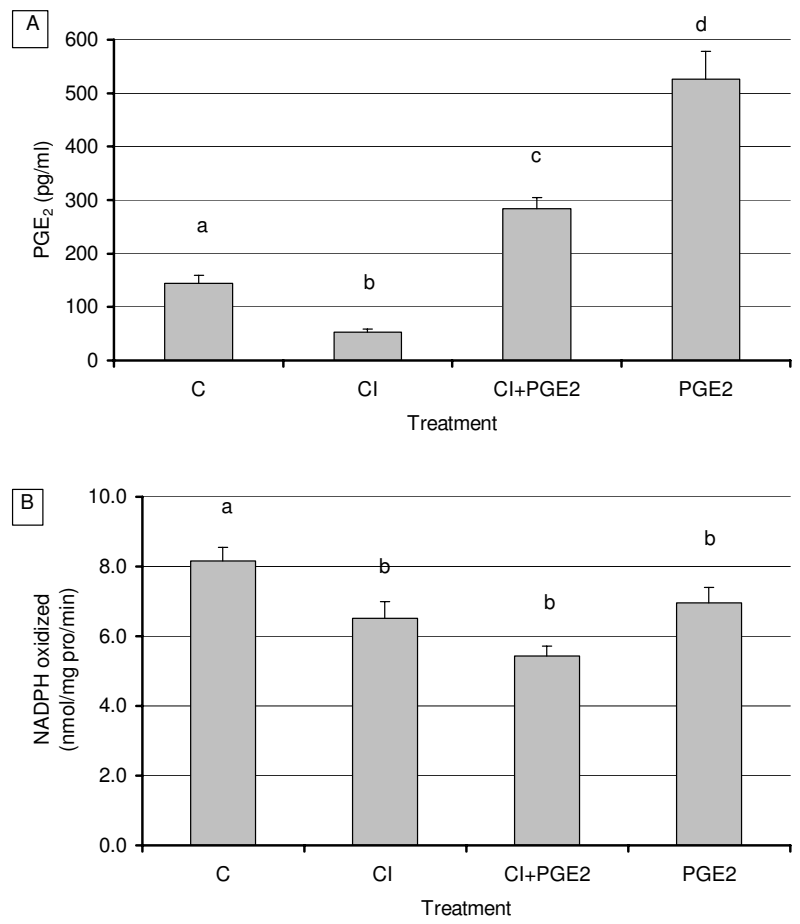

\section{Figure 6}

Effect of exogenous $\mathrm{PGE}_{2}$ and $\mathrm{COX}$ inhibition on adipocyte PGE $_{2}$ secretion (6A) and FAS activity (6B).

3T3 L-I adipocytes were grown 6-7 days post-confluence, and starved for $24 \mathrm{~h}$ in serum free media containing FA free BSA. Treatment consisted of $\mathrm{Cl}(\mathrm{I} \mu \mathrm{M}), \mathrm{PGE}_{2}(300 \mathrm{pM})$, and $\mathrm{Cl}+\mathrm{PGE}_{2}$. After 48 hours, $2 \mathrm{~mL}$ of media was removed and cells were scraped using $350 \mu \mathrm{L}$ of sucrose buffer, sonicated, and centrifuged for I hour. Media and cytosolic extract were stored at $-80^{\circ}$ Media PGE 2 levels and FAS activity were measured as described in the Materials and Methods. For all treatments $n=8$. Results represent the mean \pm SEM. Values labeled with different letters are significantly different $(p<$ 0.05). Values with the same letters do not differ significantly.

the COX enzymes by piroxicam (or other COX inhibitors, data not shown) decrease FAS activity (Fig. 1); this effect was reversed by admnistering mice EP receptor agonists. These results demonstrate that a lipogenic and receptormediated effect of $\mathrm{PGE}_{2}$, which coupled with its previously reported antilipolytic effects [11-14] likely favor triglyceride storage. To further test direct effects of $\mathrm{PGE}_{2}$ manipulation in adipocytes, we used 3T3-L1 adipocytes and used dietary polyunsaturated fatty acids (AA and EPA) as well as pharmacological means (COX inhibition) to modulate prostaglandin levels. Our goal was to test whether changes in $\mathrm{PGE}_{2}$ levels led to parallel changes in FAS activity or expression.

We report here dose-dependent increases in $\mathrm{PGE}_{2}$ levels with AA and EPA treatments ( $\mathrm{p}<0.001)$ and, as expected,
AA exhibited a more potent induction of $\mathrm{PGE}_{2}$ secretion versus EPA or control. Very limited information exists in the literature regarding physiological levels of EPA, but they are unlikely to approach those of AA due to large difference in their levels in membrane phospholipids. Studies conducted on postmenopausal women fed fish oil found the EPA levels of plasma lipids was $750 \mu \mathrm{M}[36,37]$. Our dose response studies indicate that despite the clearly powerful effect of $\mathrm{AA}$ in increasing $\mathrm{PGE}_{2}$ (compared to EPA), the latter was also able to significantly elevate $\mathrm{PGE}_{2}$ levels especially at the 200 and $500 \mathrm{uM}$ doses. Doses at $500 \mathrm{uM}$ and above visibly impacted cell viability and morphology (data not shown). Based on the manufacturer's information for cross-reactivity (and confirmed in our laboratory), the assay also detects $\mathrm{PGE}_{3}$ (cross reactivity with $\mathrm{PGE}_{2}$ antibody), which may explain at least in part increased $\mathrm{PGE}_{2}$ levels with EPA. Although the binding affinities of AA and EPA for both isoforms of COX are equivalent $(\mathrm{Km}=5 \mu \mathrm{M}), \mathrm{COX}-1$ and -2 oxygenate EPA at $\sim 10 \%$ and $\sim 35 \%$, respectively, compared to the rate for AA when added exogenously to cultured cells. Compared to AA, EPA is a poorer substrate for COX-1 in vivo[44]. Complicating this issue further is the fact that very little is known concerning the actions of $\mathrm{PGE}_{3}$ and its subsequent down stream signaling [42]. Studies in NIH 3T3 fibroblasts found that $\mathrm{PGE}_{3}$ activated the same signaling pathways as $\mathrm{PGE}_{2}$, but with much less efficiency [3]. This would imply that high levels of $\mathrm{PGE}_{3}$ might duplicate the actions of $\mathrm{PGE}_{2}$, suggesting there would be a point of diminishing returns with EPA supplementation and thus the importance of using appropriate low doses for experimentation and supplementation. It is also possible that $\mathrm{PGE}_{3}$ may bind to EP receptors with affinities that differ significantly from $\mathrm{PGE}_{2}$ [42], whereby the type and number of receptors in adipocytes would also influence the impact of EPA supplementation. While it is important to point out these differences in $\mathrm{PGE}_{2} \mathrm{vs}$. $\mathrm{PGE}_{3}$ formation, the main focus of this paper is primarily on the role of PG and COX in modulating fatty acid synthesis.

Based on our dose response data, we chose to use intermediate dosage of $150 \mu \mathrm{M}$ for the rest of our experiments. This dose is also consistent with the findings of other studies $[3,35]$, which demonstrated the ability to manipulate secreted $\mathrm{PGE}_{2}$ by using EPA to compete with AA for incorporation into membrane phospholipids and subsequent PG production.

$\mathrm{PGE}_{2}$ levels in the CI treatment group were significantly lower than controls. Although the celecoxib preferentially inhibits COX-2, no studies have shown whether it reduces $\mathrm{PGE}_{2}$ levels in adipocytes. Most published evidence indicates that inducible enzyme COX-2 is not expressed at physiologically relevant levels in mature adipocytes under normal conditions $[31,45]$. However, since we used a CI 
dose $(1 \mu \mathrm{M})$ similar to that of $\operatorname{IC}_{50}(1.2 \mu \mathrm{M}[46])$, it is plausible that constitutively expressed COX-1 activity was also inhibited at this dose. Using FAS as a marker of adipocyte lipogenesis, our data showed decreases in FAS activity with the CI treatment. In agreement with our finding, another study also showed that a non-specific COX inhibitor, aspirin, also decreases lipogenesis or levels of triacylglycerols in adipocytes [31].

The overall comparison of PGE levels for the AA, EPA, and $\mathrm{AA}+\mathrm{EPA}$ treatment groups correlated well with previously published data measuring tissue concentrations of these fatty acids in mice fed diets supplemented with these fatty acids, although the end points measured and experimental models were different in our study compared to those reported $[33,40,47]$.

Treatment of adipocytes with either EPA or AA elicited significant reductions in FAS mRNA compared to control, consistent with previously reported inhibition of FAS message by PUFA (36) in a degree of unsaturation and chain length-dependent manner $[17,48]$. Therefore, regulation of FAS expression in adipocytes by PUFA is independent of changes in prostaglandin levels. Alternatively, PG could be directly controlling FAS gene expression via a receptor-mediated mechanism. Such opposing effects may be explained by direct transcriptional effects of EPA and AA on the FAS gene. Indeed, this theory is in line with results from Deng et al. showing that degree of unsaturation correlated highly with suppression of the SREBP-1c promoter [39], the main transcription factor regulating FAS and other lipogenic genes. However, it is worth noting that since mRNA stability was not measured in these experiments, it is also possible that increased stability was responsible for the discrepancy between decreased FAS mRNA expression and small changes in FAS activity in response to PUFA treatments. It is also possible that this discrepancy is due to a longer half-life of the FAS protein such that we were unable to detect changes in enzyme activity within our treatment times (24-48 hours). Indeed, previous studies have shown that changes in FAS mRNA half-life depend on cell culture treatments and state of differentiation $[49,50]$. Another possibility is that $\mathrm{PGE}_{2}$ treatments stimulate leptin secretion (as previously documented Fain et al [15]) and elevated leptin levels may subsequently decrease lipogenesis [51]. Thus, decreased FAS expression may indirectly reflect effects of $\mathrm{PGE}_{2}$ mediated by leptin $[52,53]$. Unfortunately, due to the very low levels of leptin secretion in 3T3-L1, we were not able to assess regulation of leptin in these cells. Additional possible mechanisms may involve the antithetic actions of the EP receptors. Long et al. investigated the role of COX mediated products of AA metabolism on regulation of glucose transporter 4 (GLUT 4). They found that a 50-fold increase in endogenous $\mathrm{PGE}_{2}$ or exposure to
$10 \mu \mathrm{M}$ exogenous $\mathrm{PGE}_{2}$ resulted in an increase in cAMP concentrations, consistent with activation of the $\mathrm{EP}_{2} / \mathrm{EP}_{4}$ receptor [54]. Additionally, studies using the specific COX-2 inhibitor NS-398 on cortical collecting duct cells found that NS-398 treatment increased $\mathrm{EP}_{3}$ and $\mathrm{EP}_{4}$ receptor expression 3-fold [55]. Although the concentration of exogenous $\mathrm{PGE}_{2}$ added in our treatments was much lower, preliminary gene expression studies demonstrate that celecoxib also influenced the expression of EP receptors (specifically $\mathrm{EP}_{4}$, data not shown), which may differ from effects of aspirin or other non-specific COX inhibitors. An increase in $\mathrm{EP}_{4}$ receptors and the resulting increase in cAMP would activate a pathway that would oppose the decrease in cAMP responsible for the $\mathrm{PGE}_{2}$ mediated decrease in lipolysis. Further work with EP receptor concentration and mechanism of action is necessary to delineate the exact role of each receptor in regulating adipocyte metabolism.

One surprising finding is that $\mathrm{PGE}_{2}$ recapitulated the decrease of FAS activity and expression by COX inhibition but that combined $\mathrm{PGE}_{2}$ and celecoxib treatments further decreased FAS. These results may be due to and complicated by changes in EP receptor expression and signaling with $\mathrm{PGE}_{2}$ addition. It is also possible that the pathways mediating $\mathrm{PGE}_{2}$ effects via its receptors are different from those affected by COX inhibition. Further, COX inhibition was more potent than EPA in reducing FAS, possibly due to higher levels of the two PGE isoforms in the presence of EPA compared to control.

Overall, our studies demonstrated the ability to pharmacologically decrease production of $\mathrm{PGE}_{2}$ using the selective COX-2 inhibitor celecoxib, which resulted in a significant reduction in lipogenic enzyme activity. The use of EPA was also shown to result in lower production of $\mathrm{PGE}_{2}$ when compared to AA treatment. FAS mRNA expression was decreased by FA treatment in a manner similar to the PUFA effects seen in the liver $[16,27,28]$. Given that SREBP1C, an insulin responsive transcription factor, mediates PUFA regulation of hepatic lipogenic genes, it is possible that PUFA regulation of adipocyte metabolism modulates insulin sensitivity. Indeed, in the absence of insulin, our cells expressed significantly higher $\mathrm{PGE}_{2}$ levels than in the presence of insulin (data not shown).

Low PGE 2 levels led to decreased lipogenesis and thus a reduction in $\mathrm{PGE}_{2}$ levels would result in less inhibition of lipolysis, which coupled with reported antilipogenic effects of EPA and other polyunsaturated fatty acids would still favorably impact adipose tissue levels and result in decreased adiposity.

Further experimentation is required to determine the mechanism of action of celecoxib and EPA versus $\mathrm{PGE}_{2}$ in 
adipose tissue. Additional data on the receptor affinities and actions of $\mathrm{PGE}_{3}$, although difficult to approach at this time given the lack of data in this area, are necessary in order to understand the mechanism mediating EPA and $\mathrm{PGE}_{3}$ effects on lipid metabolism.

This study also brings to light the need for further studies on the function and impact of $\mathrm{PGE}_{3}$ in adipocytes to determine if it does in fact elicit the same responses as $\mathrm{PGE}_{2}$. If this is the case, then it may indicate a point of diminishing benefit and the need to specify a consumption range instead of recommending minimum consumption levels. Understanding the mechanisms involved with EPA metabolism takes on further importance with the FDA move to allow qualified health claims for omega-3 fatty acids [56], as this will most certainly bring more attention to these fatty acids and increase their consumption even further.

\section{Competing interests}

The authors declare that they have no competing interests.

\section{Authors' contributions}

PW carried out PG and FAS analysis studies in 3T3-L1 adipocytes and first draft of the manuscript; YM performed analyses of mouse adipose tissue; NK contributed to data analysis and manuscript writing; SK contributed to cell culture studies; MHP carried out the mouse studies; AS carried out and reviewed statistical analysis of the data; $\mathrm{KC}$ contributed to experimental design in cultured cells and to manuscript writing; $\mathrm{BHV}$ contributed to cell culture design and manuscript writing; JW carried out experimental design of the mouse studies and contributed to design of the cell culture experiment and manuscript review and editing; NMM conceived and coordinated this study, carried out the experimental design of the cell culture experiments, trained PW, YM and NK and finalized the manuscript for submission; All authors read and approved the final manuscript version.

\section{Acknowledgements}

This work was supported by a USDA CSREES NRI Grant 2005-3520015224 and by the TN agricultural experiment station. The authors wish to thank Allison Stewart for her technical assistance with the cell culture studies.

\section{References}

I. Kim S, Moustaid-Moussa N: Secretory, endocrine and autocrine/ paracrine function of the adipocyte. J Nutr 2000, 130:31|OS-31|5S.

2. Wang P, Mariman E, Renes J, Keijer J: The secretory function of adipocytes in the physiology of white adipose tissue. J Cell Physiol 2008, 216(1):3-13.

3. Bagga D, Wang L, Farias-Eisner R, Glaspy JA, Reddy ST: Differential effects of prostaglandin derived from omega -6 and omega 3 polyunsaturated fatty acids on COX-2 expression and IL-6 secretion. Proc Natl Acad Sci USA 2003, I 00(4): I75I- 1756.

4. Fain JN, Leffler CW, Cowan J, George SM, Buffington C, Pouncey L, Bahouth SW: Stimulation of leptin release by arachidonic acid and prostaglandin E2 in adipose tissue from obese humans. Metabolism 200I, 50(8):92I-928.

5. Fain JN, Madan AK, Hiler ML, Cheema P, Bahouth SW: Comparison of the release of adipokines by adipose tissue, adipose tissue matrix, and adipocytes from visceral and subcutaneous abdominal adipose tissues of obese humans. Endocrinology 2004, I 45(5):2273-2282.

6. Richelsen B: Release and effects of prostaglandins in adipose tissue. Prostaglandins Leukot Essent Fatty Acids 1992, 47(3): I II-82.

7. Hétu PO, Riendeau D: Down-regulation of microsomal prostaglandin E2 synthase- $I$ in adipose tissue by high-fat feeding. Obesity (Silver Spring) 2007, I 5(I):60-8.

8. Kuehl FA Jr, Humes JL: Direct evidence for a prostaglandin receptor and its application to prostaglandin measurements (rat-adipocytes-antagonists-analogues-mouse ovary assay). Proc Natl Acad Sci USA 1972, 69(2):480-4.

9. Gorman RR, Miller OV: Specific prostaglandin EI and AI binding sites in rat adipocyte plasma membranes. Biochim Biophys Acta 1973, 323(4):560-572.

10. Borglum JD, Pedersen SB, Ailhaud G, Negrel R, Richelsen B: Differential expression of prostaglandin receptor mRNAs during adipose cell differentiation. Prostaglandins Other Lipid Mediat 1999, 57(5-6):305-317.

II. Kather $\mathrm{H}$ : Effects of prostaglandin E2 on adenylate cyclase activity and lipolysis in human adipose tissue. Int J Obes 198I, 5(6):659-663.

12. Robertson RP, Little SA: Down-regulation of prostaglandin E receptors and homologous desensitization of isolated adipocytes. Endocrinology 1983, II3(5): 1732-8.

13. Richelsen BE, Beck-Neilsen H, Pedersen O: Prostaglandin E2 receptor binding and action in human fat cells. J Clin Endocrinol Metab 1984, 59:7-I2.

14. Strong P, Coleman RA, Humphrey PPA: Prostanoid-induced inhibition of lipolysis in rat isolated adipocytes: Probable involvement of EP3 receptors. Prostaglandins 1992, 43(6):559-566.

15. Fain JN, Leffler CW, Bahouth SW: Eicosanoids as endogenous regulators of leptin release and lipolysis by mouse adipose tissue in primary culture. J Lipid Res 2000, 4 I (10): 1689-94.

16. Mater MK, Thelen AP, Jump DB: Arachidonic acid and $\mathrm{PGE}_{2}$ regulation of hepatic lipogenic gene expression. J Lipid Res 1999 , 40(6): $1045-52$.

17. Jump DB, Clarke SD, Thelen A, Liimatta M, Ren B, Badin M: Dietary polyunsaturated fatty acid regulation of gene transcription. Prog Lipid Res 1996, 35(3):227-4I.

18. Jump DB, Thelen A, Ren B, Mater M: Multiple mechanisms for polyunsaturated fatty acid regulation of hepatic gene transcription. Prostaglandins Leukot Essent Fatty Acids 1999, 60(56):345-9.

19. Diraison F, Dusserre E, Vidal H, Sothier M, Beylot M: Increased hepatic lipogenesis but decreased expression of lipogenic gene in adipose tissue in human obesity. Am J Physiol Endocrinol Metab 2002, 282(I):E46-5I.

20. Nugent C, Prins JB, Whitehead JP, Wentworth JM, Chatterjee VK, O'Rahilly S: Arachidonic acid stimulates glucose uptake in 3T3-LI adipocytes by increasing GLUTI and GLUT4 levels at the plasma membrane. Evidence for involvement of lipoxygenase metabolites and peroxisome proliferator-activated receptor gamma. J Biol Chem 200I, 276(I 2):9|49-9I57.

21. Laneuville O, Breuer DK, Xu N, Huang ZH, Gage DA, Watson JT, Lagarde M, DeWitt DL, Smith WL: Fatty Acid Substrate Specificities of Human Prostaglandin-endoperoxide H Synthase-I and -2. J Biol Chem 1995, 270(33): 19330-19336.

22. Harris SG, Padilla J, Koumas L, Ray D, Phipps RP: Prostaglandins as modulators of immunity. Trends Immunol 2002, 23(3): I44-I 50.

23. Hyman BT, Stoll LL, Spector AA: Prostaglandin production by 3T3-LI cells in culture. Biochim Biophys Acta 1982, 7 I 3(2):375-85.

24. Richelsen $B$ : Release and effects of prostaglandins in adipose tissue. Prostaglandins Leukot Essent Fatty Acids 1992, 47(3): I7I-82.

25. Madan AK, Tichansky DS, Coday M, Fain JN: Comparison of IL-8, IL-6 and PGE(2) formation by visceral (omental) adipose tissue of obese Caucasian compared to African-American women. Obes Surg 2006, I6(10): 1342-50.

26. Hétu PO, Riendeau D: Down-regulation of microsomal prostaglandin E2 synthase- $I$ in adipose tissue by high-fat feeding. Obesity (Silver Spring) 2007, I 5(I):60-8. 
27. Kim HK, Choi S, Choi H: Suppression of hepatic fatty acid synthase by feeding alpha-linolenic acid rich perilla oil lowers plasma triacylglycerol level in rats. J Nutr Biochem 2004, I 5(8):485-92.

28. Dentin R, Benhamed F, Pégorier JP, Foufelle F, Viollet B, Vaulont S, Girard J, Postic C: Polyunsaturated fatty acids suppress glycolytic and lipogenic genes through the inhibition of ChREBP nuclear protein translocation. J Clin Invest 2005, I I 5(I0):2843-54.

29. Fain JN, Kanu A, Bahouth SW, Cowan GS Jr, Hiler ML, Leffler CW: Comparison of $\mathrm{PGE}_{2}$, prostacyclin and leptin release by human adipocytes versus explants of adipose tissue in primary culture. Prostaglandins Leukot Essent Fatty Acids 2002, 67(6):467-73.

30. Kim S, Whelan J, Claycombe K, Reath DB, Moustaid-Moussa N: Angiotensin II Increases Leptin Secretion by 3T3-LI and Human Adipocytes via a Prostaglandin-Independent Mechanism. J Nutr 2002, I 32(6): I |35- I | 40

31. Lu S, Nishimura K, Hossain MA, Jisaka M, Nagaya T, Yokota K: Regulation and role of arachidonate cascade during changes in life cycle of adipocytes. Appl Biochem Biotechnol 2004, I I8(I3): $133-53$.

32. Hansen-Petrik MB, McEntee MF, Jull B, Shi H, Zemel MB, Whelan J: Prostaglandin E2 Protects Intestinal Tumors from Nonsteroidal Anti-inflammatory Drug-induced Regression in ApcMin/+ Mice. Cancer Res 2002, 62(2):403-408.

33. Hansen-Petrik MB, McEntee MF, Chiu CH, Whelan J: Antagonism of Arachidonic Acid Is Linked to the Antitumorigenic Effect of Dietary Eicosapentaenoic Acid in ApcMin/+ Mice. J Nutr 2000, I30(5): II53-1I58.

34. Chavez JA, Holland WL, Bar J, Sandhoff K, Summers SA: Acid ceramidase overexpression prevents the inhibitory effects of saturated fatty acids on insulin signaling. J Biol Chem 2005, 280:20148-20153

35. Guo W, Wong S, Xie W, Lei T, Luo Z: Palmitate modulates intracellular signaling, induces endoplasmic reticulum stress, and causes apoptosis in mouse 3T3-LI and rat primary preadipocytes. Am J Physiol Endocrinol Metab 2007, 293(2):E576-86.

36. Wang Y, Jones Voy B, Urs S, Kim S, Bejnood M, Quigley N, Heo YR, Standridge M, Andersen B, Dhar M, Joshi M, Wortman P, Taylor JW, Chun J, Leuze M, Claycombe K, Saxton AM, Moustaid-Moussa N: The human fatty acid synthase gene and de novo lipogenesis are coordinately regulated in human adipose tissue. J Nutr 2004, 134:1032-1038.

37. Bradford MM: A rapid and sensitive method for the quantitation of microgram quantities of protein utilizing the principle of protein-dye binding. Anal Biochem 1976, 72:248-254.

38. Higdon JV, Du SH, Lee YS, Wu T, Wander RC: Supplementation of postmenopausal women with fish oil does not increase overall oxidation of LDL ex vivo compared to dietary oils rich in oleate and linoleate. J Lipid Res 200I, 42(3):407-4 I8.

39. Higdon JV, Liu J, Du SH, Morrow JD, Ames BN, Wander RC: Supplementation of postmenopausal women with fish oil rich in eicosapentaenoic acid and docosahexaenoic acid is not associated with greater in vivo lipid peroxidation compared with oils rich in oleate and linoleate as assessed by plasma malondialdehyde and F(2)-isoprostanes. Am J Clin Nutr 2000, 72(3):714-722.

40. Leray C, Andriamampandry M, Gutbier G, Raclot T, Groscolas R: Incorporation of $n-3$ fatty acids into phospholipids of rat liver and white and brown adipose tissues: $A$ time-course study during fish-oil feeding. I Nutr Biochem 1995, 6( I 2):673-680

41. Yang P, Chan D, Felix E, Cartwright C, Menter DG, Madden T, Klein RD, Fischer SM, Newman RA: Formation and antiproliferative effect of prostaglandin $E(3)$ from eicosapentaenoic acid in human lung cancer cells. J Lipid Res 2004, 45: 1030-9.

42. Deng X, Cagen LM, Wilcox HG, Park EA, Raghow R, Elam MB: Regulation of the Rat SREBP-I c Promoter in Primary Rat Hepatocytes. Biochem Biophys Res Commun 2002, 290(I):256-262.

43. Xu J, Nakamura MT, Cho HP, Clarke SD: Sterol Regulatory Element Binding Protein-I Expression Is Suppressed by Dietary Polyunsaturated Fatty Acids. A mechanism for the coordinate suppression of lipogenic genes by polyunsaturated fats. J Biol Chem I 999, 274(33):23577-23583.

44. Smith WL: Cyclooxygenases, peroxide tone and the allure of fish oil. Curr Opin Cell Biol 2005, 17: 174-82.
45. Borglum JD, Richelsen B, Darimont, Pedersen SB, Negrel R: Expression of the two isoforms of prostaglandin endoperoxide synthase (PGHS-I and PGHS-2) during adipose cell differentiation. Mol Cell Endocrinol I997, I 3 I(I):67-77.

46. Warner TD, Giuliano F, Vojnovic I, Bukasa A, Mitchell JA, Vane JR: Nonsteroid drug selectivities for cyclo-oxygenase-I rather than cyclo-oxygenase- 2 are associated with human gastrointestinal toxicity: A full in vitro analysis. Proc Natl Acad Sci USA 1999, 96(13):7563-7568.

47. Okuno M, Kajiwara K, Imai S, Kobayashi T, Honma N, Maki T, Suruga K, Goda T, Takase S, Muto Y, Moriwaki H: Perilla Oil Prevents the Excessive Growth of Visceral Adipose Tissue in Rats by Down-Regulating Adipocyte Differentiation. I Nutr 1997, I 27(9): 1752-1757.

48. Clarke SD, Jump DB: Dietary polyunsaturated fatty acid regulation of gene transcription. Annu Rev Nutr 1994, I 4:83-98.

49. Paulauskis J, Sul $\mathrm{H}$ : Cloning and expression of mouse fatty acid synthase and other specific mRNAs. Developmental and hormonal regulation in 3T3-LI cells. J Biol Chem 1988, 263(15):7049-7054.

50. Moustaid N, Sul H: Regulation of expression of the fatty acid synthase gene in 3T3-LI cells by differentiation and triiodothyronine. | Biol Chem I99|, 266(28):|8550-|8554.

5I. Bai Y, Zhang S, Kim S, Lee JK, Kim H: Obese Gene Expression Alters the Ability of 30A5 Preadipocytes to Respond to Lipogenic Hormones. J Biol Chem I996, 27 I(24): I 3939-I3942.

52. Fukuda $H$, Iritani $N$, Sugimoto $T$, Ikeda $H$ : Transcriptional regulation of fatty acid synthase gene by insulin/glucose, polyunsaturated fatty acid and leptin in hepatocytes and adipocytes in normal and genetically obese rats. Eur J Biochem 1999, 260(2):505-5II.

53. Nogalska A, Swierczynski J: Potential role of high serum leptin concentration in age-related decrease of fatty acid synthase gene expression in rat white adipose tissue. Exp Gerontol 2004 39(I): $147-150$

54. Long SD, Pekala PH: Regulation of GLUT4 gene expression by arachidonic acid. Evidence for multiple pathways, one of which requires oxidation to prostaglandin E2. J Biol Chem 1996, 27 I(2): I I38-1 I 44.

55. Nasrallah R, Laneuville O, Ferguson S, Hebert RL: Effect of COX-2 inhibitor NS-398 on expression of $\mathrm{PGE}_{2}$ receptor subtypes in M-I mouse CCD cells. Am J Physiol Renal Physiol 200I, 28I(I):FI23-I32

56. US food and drug administration [http://www.fda.gov/bbs/top ics/news/2004/NEWOIII5.html].

\section{Publish with Bio Med Central and every scientist can read your work free of charge}

"BioMed Central will be the most significant development for disseminating the results of biomedical research in our lifetime. "

Sir Paul Nurse, Cancer Research UK

Your research papers will be:

- available free of charge to the entire biomedical community

- peer reviewed and published immediately upon acceptance

- cited in PubMed and archived on PubMed Central

- yours - you keep the copyright

Submit your manuscript here:

http://www.biomedcentral.com/info/publishing_adv.asp
BioMedcentral 